\title{
Rapid Separation and Quantification of Iron in Uranium Matrix by Capillary Zone Electrophoresis (CZE)
}

\author{
Vivekchandra Mishra, Mrinal Kanti Das, Subbiah Jeyakumar, Ramesh Mahadeo Sawant, \\ Karanam Lakshminarayana Ramakumar \\ Radioanalytical Chemistry Division, Bhabha Atomic Research Centre, Mumbai, India \\ E-mail: klram@barc.gov.in \\ Received August 12, 2010; revised November 30, 2010; accepted December 2, 2010
}

\begin{abstract}
A method was developed for rapid separation and determination of iron by employing capillary zone electrophoresis (CZE) technique with direct UV detection. Iron could be separated from matrix uranium by direct injection of dissolved sample solution into capillary using a mixture of $10 \mathrm{mM} \mathrm{HCl}$ and $65 \mathrm{mM} \mathrm{KCl}(\mathrm{pH}$ $=2$ ) as background electrolyte (BGE) at an applied voltage of $15 \mathrm{kV}$. The developed method has a very high tolerance for the matrix element $\mathrm{U}(100 \mathrm{mg} / \mathrm{mL})$ and as such may not need prior separation of iron from the matrix. Iron could be separated with better than $95 \%$ recovery. The method showed a linear calibration over a concentration range 1-50 ppm of $\mathrm{Fe}(\mathrm{III})$. The migration times for the iron peak were reproducible within $1 \%$ for both pure $\mathrm{Fe}(\mathrm{III})$ and in presence of matrix uranium $(80 \mathrm{mg} / \mathrm{mL})$. The precision $(\mathrm{RSD}, \mathrm{n}=22)$ of

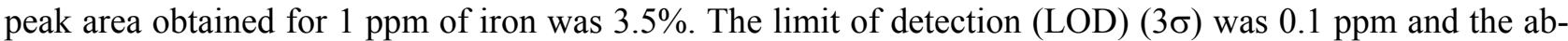
solute LOD was $9 \times 10^{-14} \mathrm{~g}$ considering the sample injection volume of $1.5 \mathrm{~nL}$. The developed method has been validated by separating and determining iron in two certified reference materials of $\mathrm{U}_{3} \mathrm{O}_{8}$. The method was applied for the determination of iron in different uranium based nuclear materials. The CZE method is versatile for routine analysis as it is simple, rapid and has simple sample preparation procedure.
\end{abstract}

Keywords: Capillary Zone Electrophoresis, Iron, Uranium, Nuclear Industry, Specification Analysis

\section{Introduction}

Separation and determination of trace elements in nuclear materials is important in nuclear industry as their performance in the reactor critically depends on their purity [1]. During the initial stages of nuclear fuel fabrication, the designers require the purity check analyses of the unfinished fuel with respect to a few elements like $\mathrm{Fe}$ and $\mathrm{Ca}$ [2]. Depending upon the concentration of iron, the designers are required to take adequate measures to achieve the desired purity.

Several methods are available for the determination of iron in nuclear materials. The methods involving ICPAES [3,4], ICP-MS [5], spectrophotometry [6], ion chromatography $[7,8]$ and HPLC [9] are well known. A disadvantage of these methods is the associated laborious and time consuming sample preparation procedures and the need for prior separation of matrix uranium using solvent extraction or ion exchange before carrying out the measurement. Also analysis of a matrix-matched reference material every time along with samples is in- dispensable to confirm the quantitative recovery of iron. This necessitates a simple, reliable, rapid and specific method to minimize the labour involved and to achieve maximum sample throughput.

In this context, the application of CZE for metal ion determination deserves increased attention due to its speed, high separation efficiency, resolving power, minimal sample and reagent requirements. Ever since the first paper concerning the indirect detection of inorganic ions by using CE in 1967 [10], the application of CE to the separation and determination of inorganic substances has increased rapidly and many papers have been published and some of critical reviews have also been summarized [11-15]. Different approaches have been reported to realize the full potential of $\mathrm{CE}$ for separation of metal ions by CE. These include employing non-aqueous media $[16,17]$, use of partial or complete complexation techniques [18, 19], using CE in conjunction with ICP-MS [20-22] and use of quantitative microchip CE [23]. Despite the increased applications to inorganic materials, the applica- 
tion of CE in nuclear industry has been somewhat limited [24,25].

The separation principle of CE is based on the differential electrophoretic mobility of charged compounds. The differences in the mobility of the analytes are related, in turn, to their charge densities, i.e., the charge-to-mass ratio. One of the problems in the analysis of metal ions by $\mathrm{CE}$ is that most of transition metal cations have almost the same mobility due to their similar size and identical charge. Obviously, the enhancement of separation selectivity is the only alternative to achieve a satisfactory resolution. Generally, there are two main approaches in this direction that imply the addition of a complexing ligand to either the carrier electrolyte or a sample solution before introduction into the capillary [26]. In the first case, the mobility of sample cations toward the cathode can be selectively moderated due to the partial complexation within the capillary, followed by the formation of metal complexes of different stability and thereby effective charge [27,28]. The second approach provides the complete pre-capillary or on- capillary conversion of metal ions into stable, charged complexes, which can move with different mobilities depending on their charge, size and stability [29]. The latter approach was exploited in the present investigation.

Several CZE methods have been reported for the determination of iron in various matrices like water, electroplating baths and cyanide complexes [30-34]. CZE separation of $\mathrm{Fe}(\mathrm{II})$ and $\mathrm{Fe}(\mathrm{III})$ was demonstrated after complexing with o-phenanthroline and EDTA respectively and the same indicates separation feasibility of $\mathrm{Fe}(\mathrm{III})$ as its EDTA complex [35]. Another study reports the separation of Fe(III) as its DTPA complex [36]. In these reported methods, for the determination of either total iron or speciation, Fe-aminocarboxylic acid anionic complex was separated from other metal-aminocarboxylic acid anionic complexes. It would be difficult to apply these methods directly for the nuclear materials like uranium compounds because U(VI) also forms anionic complex with aminocarboxylic acids. Between the aminocarboxylic acid complexes of U(VI) and Fe(III), the net negative charge of the U(VI) complex is more than that of the Fe(III)-complex (eg. Fe(III) [33] and U(VI) [37] with EDTA form Fe-EDTA ${ }^{-}$and $\mathrm{UO}_{2}-\mathrm{EDTA}^{2-}$ respectively). Due to the higher charge on the uranyl complex, the migration order follows uranium and then iron and large amount of uranium in the sample solution produces a bulk and long tailing peak, possibly masking the iron peak or affecting its recovery. It is worth mentioning that while separating the metal-aminocarboxylic acid anionic complexes, it would be difficult to achieve a large separation factor to overcome the problem of peak masking. Moreover, in these methods higher $\mathrm{pH}$ electrolyte media (typically $\mathrm{pH}$ 6-10) are used for the effective coating of CTAB on the capillary surface and subsequent formation of double layer necessary for reversing the EOF. Under such $\mathrm{pH}$ conditions, the bulk uranium will undergo hydrolysis significantly and severely obstruct the movements of ions inside the capillary path. This is because unlike the hydroxycarboxylic acids, the aminocarboxylic acids cannot prevent the hydrolysis of metals at higher $\mathrm{pH}$. Moreover, the $\mathrm{pH}$ of the sample cannot be kept low $(\mathrm{pH}<3)$ as effective complexation does not occur between metal and aminocarboxylic acids.

The aim of the work was to develop a method for the separation and quantification of iron from uranium. As direct injection of the sample solution into capillary is envisaged, significant reduction in analysis time is possible which is desirable during process control operations. At the same time, interferences from other metal cations can be eliminated due to the anionic complex formation with chloride ligand.

\section{Experimental}

\subsection{Instrumentation}

Separations were performed on a commercial capillary electrophoresis apparatus (Prince Technologies, CEC-770, Netherlands) equipped with a photodiode array detector. Fused silica capillaries of $50 \mu \mathrm{m}$ i.d. and $60 \mathrm{~cm}$ long were used. A capillary having $75 \mu \mathrm{m}$ i.d. and $60 \mathrm{~cm}$ long was also used. Sample injection was done in hydrodynamic mode by the application of 50 mbar pressure for $0.2 \mathrm{~min}$ on the sample vial which corresponds to a sample volume of $1.5 \mathrm{~nL}$. System DAX software was used for data acquisition. Direct UV detection was performed at $214 \mathrm{~nm}$. All the experiments were conducted at room temperature $\left(25-27^{\circ} \mathrm{C}\right)$. The $\mathrm{pH}$ measurements were done with a $\mathrm{pH}$ meter (Eutech, Tutor-model, Malaysia).

\subsection{Reagents and Solutions}

Standard stock solution of Fe(III) was prepared by dissolving $\mathrm{Fe}\left(\mathrm{NO}_{3}\right)_{3} \bullet 9 \mathrm{H}_{2} \mathrm{O}(99.99 \%$, Aldrich Chemicals,

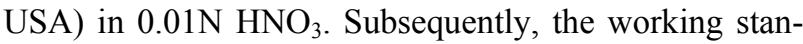
dards were made from the stock by appropriate dilutions. High purity $\mathrm{HCl}$ and $\mathrm{HNO}_{3}$ acids (suprapure, MERCK, Germany) were used for the sample and electrolyte preparations. Potassium chloride (GR grade, MERCK, Germany) was used. Nuclear grade $\mathrm{UO}_{2}$ (NFC, India) was used for the preparation of standard uranium solution and the concentration of $U$ was obtained from biamperometric determination [38]. All solutions, electrolytes 
and standard solutions were prepared with ultrapure water (18 M $\Omega$ ) obtained from a MilliQ-Academic System (Millipore, India).

\subsection{Procedure for Conditioning Capillary and Sample Injection}

Procedures for conditioning capillary, rinsing with electrolyte, hydrodynamic injection of the samples and rerinsing were programmable and these are defined for sequential execution. Briefly, the capillary was washed with $0.2 \mathrm{M} \mathrm{NaOH}$ for $15 \mathrm{~min}$ and with water for $10 \mathrm{~min}$ followed by rinsing with BGE for $15 \mathrm{~min}$. About $1.5 \mathrm{~nL}$ of the sample solution was injected into the capillary hydrodynamically by applying 50 mbar pressure for 0.2 min. A potential of $15 \mathrm{kV}$ was applied during the sample run and in between two sample runs, the capillary was again rinsed with BGE for $5 \mathrm{~min}$ to minimize memory effect, if any.

\section{Results and Discussion}

Generally, capillary zone electrophoresis (CZE) is employed for the separation of metal ions with comparable concentrations. Separating trace amounts of a metal cation present in another metal matrix is a difficult task in any high performance separation technique. However, achieving such separations offer advantages like hassle free sample preparation viz. no need of matrix separation, no uncertainty on analyte recovery and reduction in overall analysis time. Since the dissolved uranium sample solution will have high ionic strength, the direct injection of sample into the capillary can cause certain difficulties such as 1) undesirable peak broadening may occur if the conductance of sample zone $\left(\lambda_{\mathrm{s}}\right)$ becomes higher than the conductance of the $\left.\operatorname{BGE}\left(\lambda_{B}\right), 2\right)$ change in the zeta potential and variation in the magnitude of EOF occur due to adsorption of matrix cation on the surface of capillary and altering the migration time of all species significantly, 3) poor precision on the migration time due to the delayed desorption of the matrix cations resulting in long tailing or asymmetry, 4) poor separation efficiency with band broadening (the plate height increases when sample concentration is more) due to overloading of the capillary with matrix ions and 5) severe efficiency loss due to large difference in viscosities of sample and BGE.

Despite these difficulties, direct separation of trace analyte in presence of bulk matrix is feasible in CZE provided the method satisfies two conditions: 1) the analyte and the matrix elements should have large difference in their relative mobilities and 2) the mobility of the analyte should be faster than matrix element. Under these conditions, the analyte reaches the detector much earlier than the matrix element and therefore, it will be free from matrix effects. In the present case, since both uranyl and ferric ions (in their hydrated form) have little difference in their charge densities, it is difficult to separate them under normal conditions and addition of a complexing agent is essential for their separation. The organic ligands reported in literature for complexing Fe(III) in CE studies [30-36,39] may not be suitable in the present case due to the reasons already mentioned above. Hence, it was proposed to consider chloride as ligand as well as carrier electrolyte since its complexation ability with $\mathrm{UO}_{2}{ }^{2+}$ and $\mathrm{Fe}^{3+}$ ions is different and they tend to form cationic complexes of different charges. Moreover, the chloride medium enables the direct detection of selected metal ions $[40,41]$ including iron.

At lower concentrations of chloride ion $(<0.5 \mathrm{M})$, the uranyl ion predominantly forms $\mathrm{UO}_{2} \mathrm{Cl}^{+}$complex $[42,43]$ in the $\mathrm{pH}$ range 2-3. Further, the formation of anionic complexes viz. $\mathrm{UO}_{2} \mathrm{Cl}_{3}{ }^{-}, \mathrm{UO}_{2} \mathrm{Cl}_{4}{ }^{2-}$, and $\mathrm{UO}_{2} \mathrm{Cl}_{5}{ }^{3-}$ occurs only when the chloride concentration exceeds $5 \mathrm{M}$. Similarly, though $\mathrm{Fe}(\mathrm{III})$ forms $\mathrm{FeCl}^{2+}, \mathrm{FeCl}_{2}^{+}, \mathrm{FeCl}_{3}$ and $\mathrm{FeCl}_{4}^{-}$complexes, only $\mathrm{FeCl}^{2+}$ is predominant at low chloride concentrations [44]. The formation constants (log values) for the $\left[\mathrm{UO}_{2} \mathrm{Cl}\right]^{+}$and $[\mathrm{FeCl}]^{2+}$ complexes ( 0.17 and and 1.52 respectively) show that the $\mathrm{Fe}^{+3}$ has more affinity towards chloride complex formation $[43,45]$ than $\mathrm{UO}_{2}{ }^{2+}$. Therefore, at low chloride concentrations $\mathrm{UO}_{2}{ }^{2+}$ and $\mathrm{Fe}^{+3}$ form $\left[\mathrm{UO}_{2} \mathrm{Cl}\right]^{+}$and $[\mathrm{FeCl}]^{2+}$ complexes respectively and their electrophoretic mobilities will change significantly due to charge differences and their separation from each other may become feasible. Complex formation between chloride and divalent transition metal ions such as $\mathrm{Zn}(\mathrm{II}), \mathrm{Cu}(\mathrm{II}), \mathrm{Cd}(\mathrm{II}), \mathrm{Mn}$ (II) etc., is readily achieved and the complexes are remarkably stable [46]. These complexes are either anionic or neutral in nature [47] and do not cause any interference. The absorbance of the peak for iron as $[\mathrm{FeCl}]^{2+}$ complex was measured at $214 \mathrm{~nm}$ [45].

\subsection{Optimization of Background Electrolyte}

A mixed solution of $\mathrm{HCl}$ and $\mathrm{KCl}$ was selected as BGE. The $\mathrm{HCl}$ solution is the carrier electrolyte and it prevents the hydrolysis of iron, uranium and their chloride complexes by providing lower $\mathrm{pH}$ whereas $\mathrm{KCl}$ provides adequate chloride (ligand) ions inside the capillary to prevent the decomposition of complexes. All the separations were carried out with $15 \mathrm{kV}$ applied voltage.

Initially the separation of $\mathrm{Fe}$ (III) was performed with $10^{-2}, 10^{-3}, 10^{-4}$ and $10^{-5} \mathrm{M} \mathrm{HCl}$ solutions corresponding to

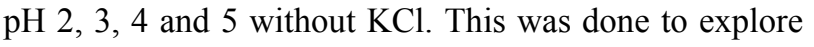


the feasibility of separating iron with low ionic strength electrolytes, which minimize joule heat generation. The standard iron solutions were also prepared in the respective $\mathrm{HCl}$ solutions in order to have almost identical composition in the BGE and standards. Figure 1 shows the overlay of electropherograms obtained for each carrier electrolyte. It is seen from the figure that decreasing the $\mathrm{pH}$ of the carrier electrolyte decreased the migration time of Fe(III) peak with substantial peak broadening. This was unexpected because increasing $\mathrm{pH}$ of the carrier electrolyte typically causes reduction in the migration time. However, the change in migration time in this case may be possibly due to following three reasons. Firstly, on increasing the $\mathrm{pH}$, the silanol group of the capillary dissociates considerably resulting in negative charges on the surface of fused silica. These negatively charged sites attract the free metal ions of iron. Hence, transient retention of iron on the capillary surface occurs, which leads to increase in migration time, band broadening and loss in sensitivity. Secondly, at higher $\mathrm{pH}$ solutions the extent of complex formation is affected due to lower concentrations of chloride. Thirdly, when the $\mathrm{pH}$ is above 2, the hydrolysis of Fe(III) and its chloride complexes may probably occur and form neutral species (hydroxides) as reported in the literature [44].

The influence of electrolyte $\mathrm{pH}$ on the separation did not result in any definite conclusion because the total chloride concentration at each $\mathrm{pH}$ condition was not kept constant. Hence, the influence of $\mathrm{pH}$ on the separation of iron at constant chloride concentration and the effect of chloride concentration under different $\mathrm{pH}$ conditions were examined. For this, three sets of solutions corresponding to $\mathrm{pH} 2,3$ and 4 were prepared. In each set, the $\mathrm{pH}$ was maintained at the pre-selected value by keeping a fixed concentration of $\mathrm{HCl}$ but the total chloride content was varied from 30 to $100 \mathrm{mM}$ by adding calculated amount of $\mathrm{KCl}$. With $\mathrm{pH} 2$ electrolyte, on increasing chloride concentration, the migration time of iron increased slightly but not significantly and at the same time, the corresponding peak area increased up to a chloride concentration of $75 \mathrm{mM}(10 \mathrm{mM} \mathrm{HCl}+65 \mathrm{mM} \mathrm{KCl})$. Further increase in chloride concentration caused only marginal changes in the peak areas (Figure 2). On the other hand, electrolytes of $\mathrm{pH} 3$ and $\mathrm{pH} 4$ brought about severe base line drift and huge noise when the chloride concentration was increased.

During the separation, there may be a little change in the electrolyte $\mathrm{pH}$ due to applied potential and protonation of silinol groups. This change can alter the migration time of iron. However, this effect was found to be insignificant when iron was separated with electrolytes of $\mathrm{pH}$ $1.8,2.0$ and 2.2 as these electrolytes brought about migration time of iron peak within $1 \%$ precision $(\mathrm{RSD}, \mathrm{n}=$ 5 in each $\mathrm{pH}$ condition). Based on these, a BGE of 10 $\mathrm{mM} \mathrm{HCl}$ and $65 \mathrm{mM} \mathrm{KCl}(\mathrm{pH} 2)$ was chosen for further studies.

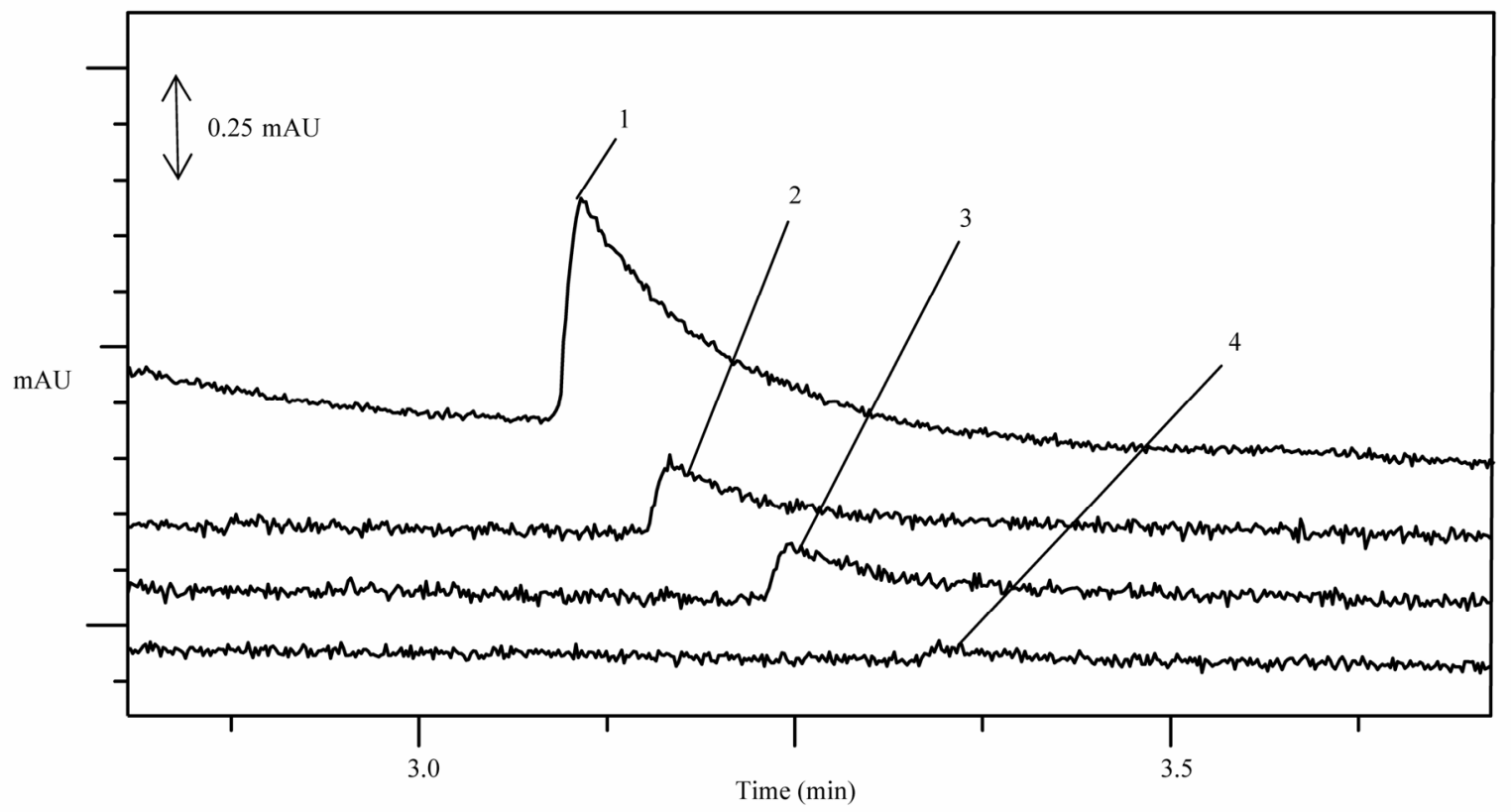

Figure 1. Electropherograms obtained for a standard iron solution ( $25 \mathrm{mg}^{-\mathrm{L}^{-1}}$ ) with BGEs of different $\mathrm{pH} .1$ ). $10^{-2} \mathrm{M} \mathbf{H C l}$ BGE corresponding to $\mathrm{pH} 2 ; 2$ ). $10^{-3} \mathrm{M} \mathrm{HCl}$ BGE corresponding to $\mathrm{pH} \mathrm{3;} 3$ ). $10^{-4} \mathrm{M} \mathrm{HCI} \mathrm{BGE} \mathrm{corresponding} \mathrm{to} \mathrm{pH} 4$ and 4 ). $10^{-5}$ M HCl BGE corresponding to pH 5, Conditions: Capillary: $60 \mathrm{~cm} \times 50 \mu \mathrm{m}$, Applied voltage: $15 \mathrm{kV}$. Detection: direct UV at $215 \mathrm{~nm}$. 



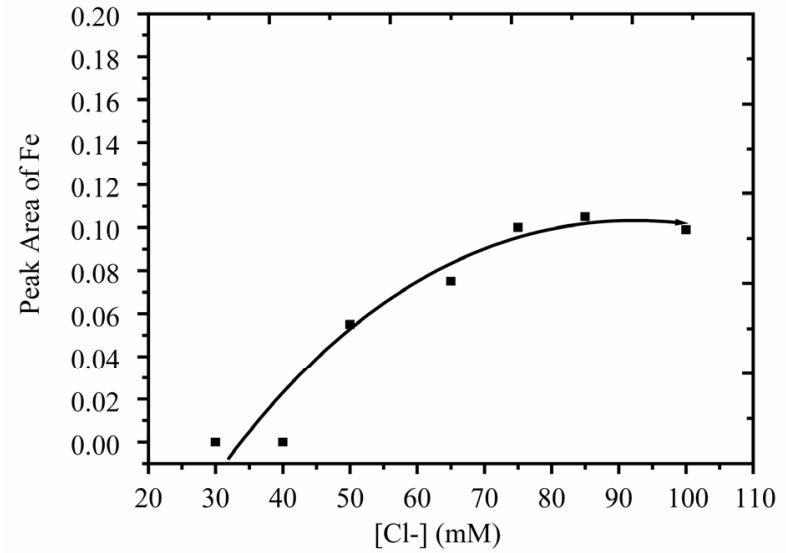

Figure 2. Effect of total chloride concentration on the peak area of iron obtained with pH 2. (BGEs were of $10^{-2} \mathrm{M} \mathrm{HCl}$ (fixed) and varying amounts of $\mathrm{KCl}$ ). Capillary: $60 \mathrm{~cm} \times 50$ $\mu \mathrm{m}$, Applied voltage: $15 \mathrm{kV}$; Detection: direct UV at 214 nm.

The migration of the matrix ion, $\mathrm{UO}_{2}{ }^{2+}$ and other common ions such as $\mathrm{Cu}(\mathrm{II}), \mathrm{Ni}(\mathrm{II}), \mathrm{Zn}(\mathrm{II}), \mathrm{Mn}(\mathrm{II})$, $\mathrm{Co}(\mathrm{II}), \mathrm{Cd}(\mathrm{II}), \mathrm{Cr}(\mathrm{III}), \mathrm{Al}(\mathrm{III}), \mathrm{Ca}(\mathrm{II}), \mathrm{Mg}(\mathrm{II}), \mathrm{Sr}(\mathrm{II})$, $\mathrm{Ba}(\mathrm{II}), \mathrm{Na}$ and $\mathrm{K}$, which are expected to be present in the actual samples in very low concentrations, were investigated. The uranyl ion (as $\mathrm{UO}_{2} \mathrm{Cl}^{+}$) appeared much later than iron peak whereas the transition, alkali and alkaline earth metal cations could not be detected even up to 60 min. at the entire range of absorption measurements from $214 \mathrm{~nm}$ to $240 \mathrm{~nm}$. The probable explanation for this is the migration of these metal complexes (mainly in anionic form) towards the anode and also the EOF at $\mathrm{pH} 2$ is expected to be significantly small.

The peaks of Fe(III) and U(VI) were confirmed by injecting the standard mixture solutions having varying concentrations.

\subsection{Optimization of Applied Voltage}

The relation between efficiency $(\mathrm{N})$ and applied voltage is expressed as, $\mathrm{N}=\mu_{\mathrm{ep}} \mathrm{V} / 2 \mathrm{D}_{\mathrm{S}}$ where $N$ is efficiency, $V$ is applied voltage and $D_{s}$ is the diffusion co-efficient [48]. Higher values of $\mathrm{N}$ can be achieved by the application of high voltage because it reduces the dispersion time of the sample zone. Hence, the effect of applied voltage on the mobilities of iron and uranium ions was investigated by varying the potential from 5 to $30 \mathrm{kV}$. There was a considerable change in the mobilities of $\mathrm{Fe}$ and $\mathrm{U}$ and their peak reproducibility when the potential was raised beyond $20 \mathrm{kV}$. It was also seen that at higher voltages the resolution between $\mathrm{Fe}$ and $\mathrm{U}$ was poor due to peak broadening. A plot of current Vs applied voltage showed that the current and voltage was non linear beyond $18 \mathrm{kV}$ indicating the inability of capillary to dissipate the Joule heat. Therefore, an applied voltage of $15 \mathrm{kV}$ was adopted as optimal. Typical electropherograms obtained for $\mathrm{Fe}(\mathrm{III})$ of different concentrations under the optimized conditions have been shown in Figure 3.

\subsection{Matrix Element Tolerance}

The tolerance of matrix element on the separation and determination of $\mathrm{Fe}$ (III) was investigated by spiking 50 ppm of $\mathrm{Fe}$ (III) into uranium solutions of different concentrations (0.1-90 $\mathrm{mg}$ of $\mathrm{U} / \mathrm{mL})$. An un-spiked uranium solution was treated as blank. A standard solution containing $50 \mathrm{ppm}$ of $\mathrm{Fe}(\mathrm{III})$ was taken as a calibration standard for determining concentration of $\mathrm{Fe}$ (III) in the iron-spiked uranium solutions. The values obtained for the spiked solutions are in good agreement with the expected value and the overall precision and accuracy was better than $5 \%$ as shown in Table 1 . The studies also show the recovery of iron in the presence of bulk uranium was unaffected and the recovery of iron was found between 97 and 103\%. An electropherogram obtained for $5 \mathrm{ppm}$ of $\mathrm{Fe}(\mathrm{III})$ with $80 \mathrm{mg}$ of $\mathrm{U} / \mathrm{mL}$ is also shown in Figure 3.

\subsection{Validation of Method}

\subsubsection{Specificity of CZE Method}

Owing to the minute differences in the charge densities of many transition metal cations including iron, they may interfere with iron. Therefore, the migrations of some selective metal cations were examined. The iron peak was totally interference free from the metal ions like $\mathrm{Cu}(\mathrm{II}), \mathrm{Pb}(\mathrm{II}), \mathrm{Ni}(\mathrm{II}), \mathrm{Zn}(\mathrm{II}), \mathrm{Mn}(\mathrm{II}), \mathrm{Co}(\mathrm{II}), \mathrm{Cd}(\mathrm{II})$, $\mathrm{Cr}(\mathrm{III})$, alkali, alkaline earth metals as they were not detected up to a concentration of $300 \mathrm{ppm}$ of each metal ion. Hence, the CZE separation is highly specific for $\mathrm{Fe}(\mathrm{III})$.

Table 1. Recoveries of spiked iron in uranium solutions of various concentrations.

\begin{tabular}{ccccc}
\hline No & $\begin{array}{c}\text { Uranium } \\
(\mathrm{ppm})\end{array}$ & $\begin{array}{c}\text { Fe spiked in U } \\
\text { solution }(\mathrm{ppm})\end{array}$ & $\begin{array}{c}\text { Fe determined } \\
\text { by CE (ppm) }\end{array}$ & $\begin{array}{c}\text { \% of } \\
\text { recovery }\end{array}$ \\
\hline 1 & 10 & 50 & $48.6 \pm 2.4$ & 97.2 \\
2 & 1000 & 50 & $48.3 \pm 2.7$ & 96.6 \\
3 & 10000 & 50 & $51.9 \pm 2.9$ & 103.8 \\
4 & 50000 & 50 & $47.9 \pm 3.1$ & 95.8 \\
5 & 75000 & 50 & $52.3 \pm 2.6$ & 104.6 \\
6 & 90000 & 50 & $51.8 \pm 2.8$ & 103.6 \\
\hline
\end{tabular}

${ }^{a}$ mean value of three determinations $(n=3)$. 


\subsubsection{Linearity}

A linear relationship between peak area and concentration was obtained in the $1-50 \mathrm{ppm}$ of $\mathrm{Fe}$ (III) and the correlation coefficient obtained in this case was 0.9995 .

\subsubsection{Limit of Detection (LOD) and Limit of Quantification (LOQ)}

The detection limit for a signal-to-noise ratio of 3 for Fe(III) was $0.1 \mathrm{ppm}$. The absolute LOD is $9 \times 10^{-14} \mathrm{~g}$; considering the sampling volume as $1.5 \mathrm{~nL}$. An e-gram obtained for $0.08 \mathrm{ppm}$ of iron, which is very close to the detection limit was also shown in Figure 3. The limit of quantification was approximately $0.6 \mathrm{ppm}$ (basis of $\mathrm{S} / \mathrm{N}$ ratio of 6).

\subsubsection{Reproducibility}

The reproducibility was studied by making ten consecutive runs of two standard solutions of iron, in which the first solution has only $5 \mathrm{ppm}$ of iron and the second has 5 ppm of iron in presence of $80 \mathrm{mg}$ of $\mathrm{U} / \mathrm{mL}$ of uranium. The precisions ( $\% \mathrm{RSD}, \mathrm{n}=10)$ obtained for peak area for the first and second solutions were 0.99 and 1.88 respectively as shown in Figure 4(a). However, replicate analysis $(n=20)$ of a $1 \mathrm{ppm}$ iron standard solution under the optimized conditions brought about a precision (\% RSD) of 3.5 as shown in Figure 4(b). Since the analyte in the real sample is present in uranium matrix, the reproducibility of migration time was also studied with the same two $5 \mathrm{ppm}$ iron solutions mentioned above. The precisions $(\% \mathrm{RSD}, \mathrm{n}=10)$ of migration time obtained for the pure iron and with uranium were 0.97 and 1.02 respectively (Table 2).

\subsubsection{Comparative Analysis with Certified Reference Materials}

To check the recovery of iron and to validate the developed procedure, two reference materials of $\mathrm{U}_{3} \mathrm{O}_{8}$ matrix (namely ILCE-4 and ILCE-5), which were indigenously prepared, characterized and certified by the Department of Atomic Energy, India [49] were used for the trace elements.

Accurately weighed quantities of the standards (in the range of $0.3-0.4 \mathrm{~g}$ ) were dissolved in $5 \mathrm{~mL}$ of high purity Conc. $\mathrm{HNO}_{3}$ and the solution was heated to near dryness using a hot plate under controlled heating and this procedure was repeated twice to ensure the complete dissolution. Further $3.5 \mathrm{~mL}$ of $0.01 \mathrm{~N} \mathrm{HCl}(\mathrm{pH} 2)$ acid solution was added at warm condition. The $\mathrm{pH}$ of the solution was measured using a combined $\mathrm{pH}$ electrode meant for small volume measurements and the $\mathrm{pH}$ was adjusted using $0.01 \mathrm{~N} \mathrm{HCl}$ solution, if required. Prior to sample injection, the solution was transformed into a standard volumetric flask and made up to $5 \mathrm{~mL}$ using $0.01 \mathrm{~N} \mathrm{HCl}$.

The dissolution was carried out with nitric acid because it oxidizes iron and uranium to their highest oxidation states as Fe(III) and U(VI) respectively. Since both elements exhibit their highest oxidation states, their

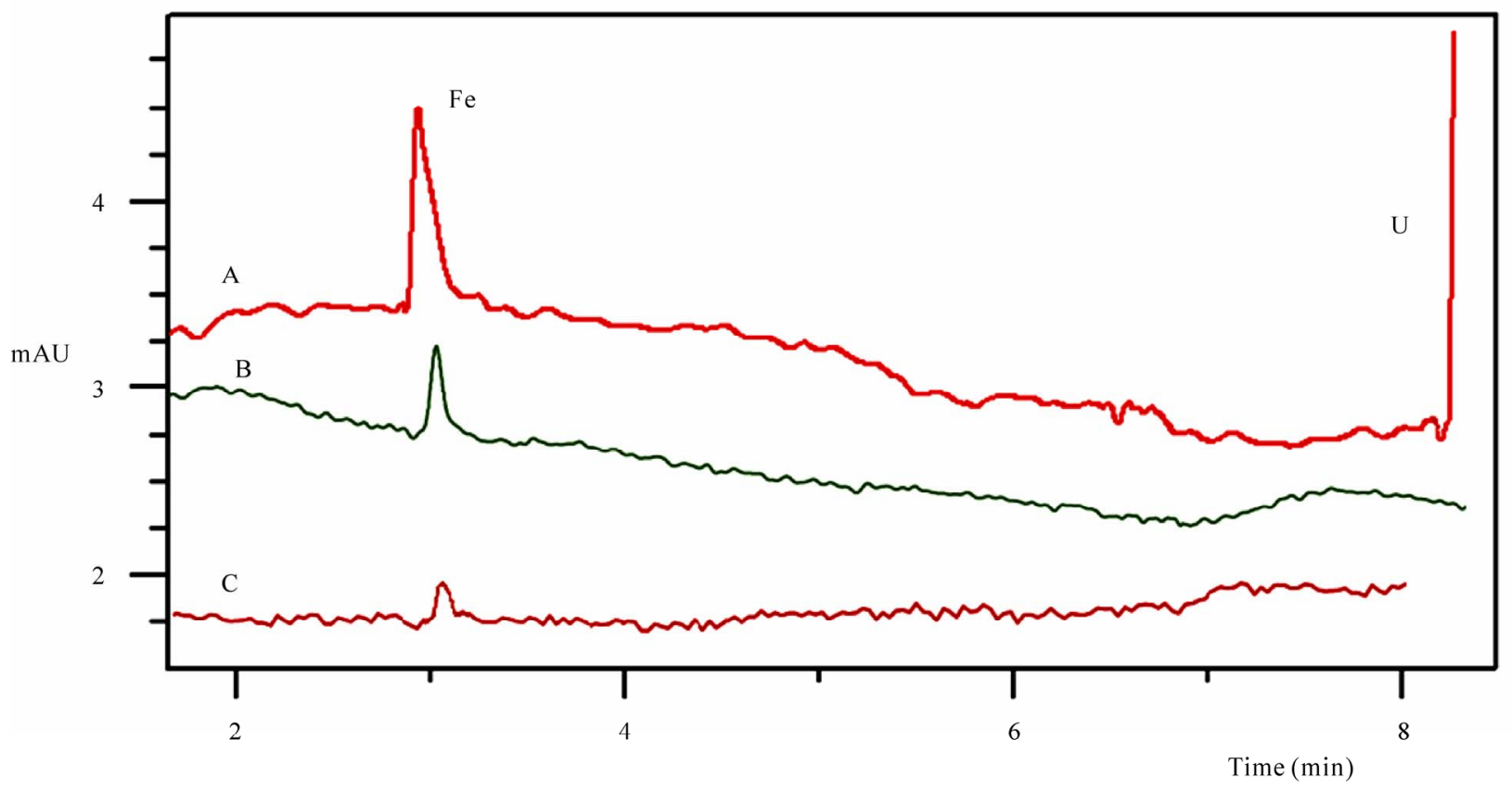

Figure 3. Electropherograms obtained for a standard solution of $\mathrm{Fe}(\mathrm{III})$ and Uranium. (A) Fe(III) (5 $\mu \mathrm{g} / \mathrm{mL})+\mathrm{U}(\mathrm{VI})(80,000$

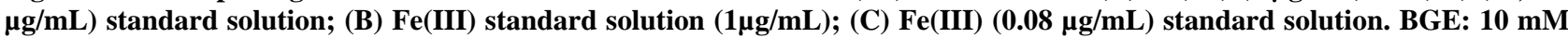
$\mathrm{HCl}$ in $65 \mathrm{mM} \mathrm{KCl}$ (pH 2), Conditions: Capillary: $60 \mathrm{~cm} \times 50 \mu \mathrm{m}$, Applied voltage: $15 \mathrm{kV}$. Detection: direct UV at $214 \mathrm{~nm}$. 


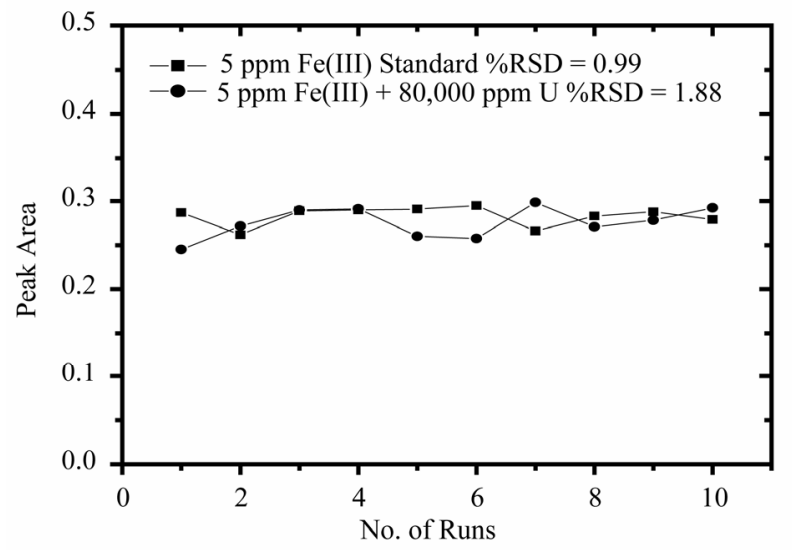

(a)

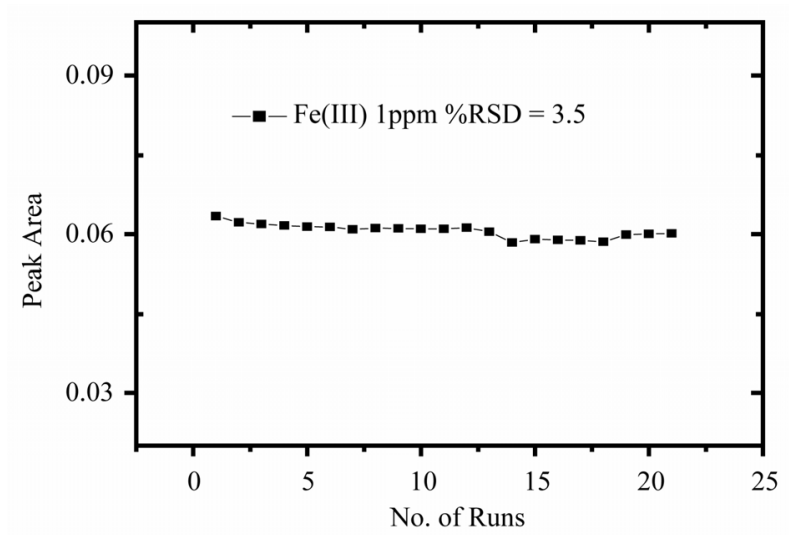

(b)

Figure 4. (a) Reproducibility of $\mathrm{Fe}(\mathrm{III})$ peak area $(\mathrm{n}=10)$ obtained for $5 \mu \mathrm{g} / \mathrm{mL}$ of Fe with and without presence of $80,000 \mathrm{\mu g} / \mathrm{mL}$ of $\mathrm{U}$; (b) for a $1 \mathrm{ppm}$ Fe standard solution ( $\mathrm{n}=$ 22). Conditions are as same as in Figure 3.

Table 2. Reproducibility of migration time of $\mathrm{Fe}$ (III) (5 ppm) with and without presence of $80 \mathrm{mg}$ of $U / \mathrm{mL}(n=10)$.

\begin{tabular}{cc}
\hline & Migration time (min) \\
\hline $\mathrm{Fe}(\mathrm{III})$ alone & $\mathrm{Fe}(\mathrm{III})$ with $80 \mathrm{mg}$ of $\mathrm{U}(\mathrm{VI}) / \mathrm{mL}$ \\
$3.088(\mathrm{RSD}, 0.97 \%)$ & $3.133(\mathrm{RSD}, 1.09 \%)$ \\
\hline
\end{tabular}

combination cannot be a redox couple. Further the formation of $\mathrm{Fe}(\mathrm{II})$ is not possible as it has least stability in nitric and hydrochloric acid media and therefore, the sample dissolution ensures all iron in its +3 state. The entire sample preparation process typically takes around 30 minutes whereas in other methods like ICP-AES, ICP-MS and ion chromatography etc. lasts for few hours as these methods require the separation of matrix element by following solvent extraction or ion exchange procedures. Table 3 compares the results obtained for the two reference materials and the values obtained by this method are in good agreement with the certified values.

\subsection{Real Sample Analysis}

The method was applied to nine uranium based fuel samples from an advanced fuel fabrication facility. The samples are either in metallic or oxide form of uranium. Samples were dissolved by following the procedure as described above for the standard reference materials (ILCE-4 and ILCE-5). Depending on the concentration of $\mathrm{Fe}$ obtained from the first run of the sample, further dilution was carried out, to adjust the analyte concentrations to the linearity range of method calibration. Table 4 lists the typical iron contents determined in the samples,

Table 3. Comparison between iron determination via the developed method and certified method.

\begin{tabular}{|c|c|c|c|c|c|}
\hline \multirow{2}{*}{ No. } & \multirow{2}{*}{$\begin{array}{l}\text { Reference } \\
\text { Std. code }\end{array}$} & \multicolumn{3}{|c|}{ Concentration of $\mathrm{Fe}\left(\mathrm{ppm}_{\mathrm{w}}\right)$} & \multirow{2}{*}{$\begin{array}{c}\% \text { of } \\
\text { deviation }\end{array}$} \\
\hline & & obtained & mean & Certified & \\
\hline \multirow{5}{*}{1.} & \multirow{5}{*}{ ILCE-IV } & 163.2 & \multirow{5}{*}{$163.5 \pm 2.8$} & \multirow{5}{*}{170} & \multirow{5}{*}{3.8} \\
\hline & & 160.3 & & & \\
\hline & & 167.1 & & & \\
\hline & & 161.6 & & & \\
\hline & & 165.5 & & & \\
\hline \multirow{5}{*}{2.} & \multirow{5}{*}{ ILCE-V } & 278.8 & \multirow{5}{*}{$275.2 \pm 2.9$} & \multirow{5}{*}{290} & \multirow{5}{*}{5.4} \\
\hline & & 276.9 & & & \\
\hline & & 270.9 & & & \\
\hline & & 275.4 & & & \\
\hline & & 274.0 & & & \\
\hline
\end{tabular}

Table 4. Results obtained for the samples.

\begin{tabular}{cc}
\hline Sample code & Fe (ppm) \\
\hline M1 & $882 \pm 52$ \\
M2 & $1311 \pm 70$ \\
M3 & $753 \pm 37$ \\
M4 & $801 \pm 36$ \\
M5 & $913 \pm 46$ \\
U1 & $318 \pm 19$ \\
U2 & $723 \pm 33$ \\
U3 & $626 \pm 29$ \\
U4 & $389 \pm 18$ \\
\hline
\end{tabular}

${ }^{a}$ mean value of three determinations $(n=3)$. 


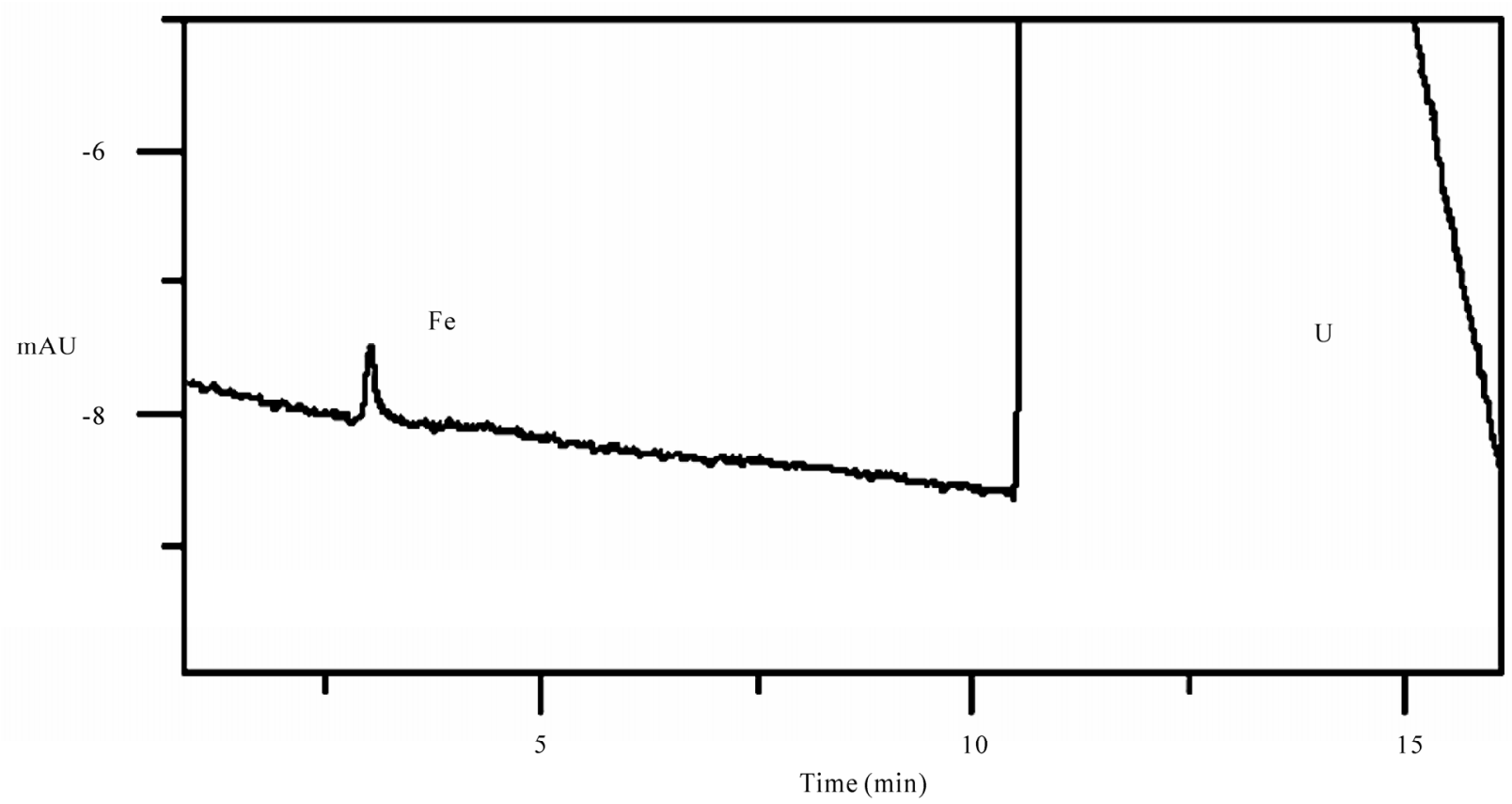

Figure 5. A typical electropherogram obtained for a sample solution. Conditions are same as in Figure 3.

where the sample codes " $\mathrm{M}$ " and " $\mathrm{U}$ " refer to metallic and oxides of uranium respectively.

\subsection{Advantages of the CZE Method}

1) Specific for iron and no interference from transition and other common metal ions.

2) Possesses high tolerance for background matrix and therefore, pre separation of matrix is not required.

3) Very simple sample preparation.

4) Simple and rapid separation. Typically it takes around 10 minutes for a sample run.

5) Provides good precisions on migration time as well as peak area of the analyte.

6) Recovery of the analyte is more than $95 \%$.

7) Generation of minimum analytical waste as there was not any additional wet handling other than the sample dissolution.

\section{Conclusions}

A rapid, reproducible and simple CZE method for the determination of iron in uranium matrix has been demonstrated. The method involved chloride complexation, where cationic chloride complexes of iron as well as uranium are selectively formed and this made the CZE separation of iron from uranium feasible. The chloride complex of iron allows direct detection at $214 \mathrm{~nm}$ with satisfactory limit of detection. The capability of the method for determining iron with high background of the matrix element was proved by analyzing matrix match reference materials. The method was applied successfully to the determination of iron in different uranium based fuel materials and is adoptable for routine analyses.

\section{Acknowledgements}

Authors are thankful to Dr. V. Venugopal, Director, RC $\&$ IG, BARC for his kind support. Sincere thanks are due to Mrs. Vaibhavi V. Raut for carrying out the experiments.

\section{References}

[1] M. V. Ramaniah, "Analytical Chemsitry of Fast Reactor Fuels - A Review," Pure and Applied Chemistry, Vol. 54, No. 4, 1982, pp. 889-908. doi:10.1351/pac198254040889

[2] H. C. Bailly, D. Menessier and C. Prunier, "The Nuclear Fuel of Pressurized Water Reactors and Fast neutron Reactors: Design and Behavior," Lavoisier Publishing Inc., Paris, 1999.

[3] K. S. Rao, T. Balaji, T. P. Rao, Y. Babu and G. R. K. Naidu, "Determination of Iron, Cobalt, Nickel, Manganese, Zinc, Copper, Cadmium and Lead in Human Hair Inductively Coupled Plasma-Atomic Emission Spectrometry," Spectrochim Acta Part B, Vol. 57, No. 8, 2002, pp. 1333-1338. doi:10.1016/S0584-8547(02)00045-9

[4] M. Gopalakrishnan, K. Radhakrishnan, P. S. Dhami, V. T. Kulkarni, M. V. Joshi, A. B. Patwardhan, A. Ramanujam and J. N. Mathur, "Determination of Trace Impurities in Uranium, Thorium and Plutonium Matrices by Solvent Extraction and Inductively Coupled Atomic Emission 
Spectrometry,” Talanta, Vol. 44, 1997, pp. 169-176. doi:10.1016/S0039-9140(96)02027-9

[5] H. Vanhoe, C. Vandecasteele, J. Versieck and R. Dams, "Determination of Iron, Cobalt, Copper, Zinc, Rubidium, Molybdenum and Cesium in Human Serum by Inductively Coupled Mass Spectrometry," Analytical Chemistry, Vol. 61, No. 17, 1989, pp. 1851-1857. doi:10.1021/ac00192a014

[6] Z. Marczenko and M. Balcerzak, "Separation, Preconcentration and Spectrophotometry in Inorganic Analysis," Elsevier, 2000, pp. 226-237.

[7] A. Kelkar, A. Prakash, M. Afzal, J. P. Panakkal and H. S. Kamath, "Determination of Alkali, Alkaline Earth and Transition Metal Ions in $\mathrm{UO}_{2}, \mathrm{ThO}_{2}$ Powders and Sintered (Th,U)O $\mathrm{O}_{2}$ Pellets by Ion Chroamtography," Journal of Radioanalytical and Nuclear Chemistry, Vol. 284, No. 2, 2010, pp. 443-449. doi:10.1007/s10967-010-0491-y

[8] V. V. Raut, M. K. Das, S. Jeyakumar and K. L. Ramakumar, "HPIC Separation and Quantification of $\mathrm{Ca}$ and Fe in Uranium Metal and Alloy Compounds," Proceedings SESTEC-2008, Delhi, 12-14 March 2008.

[9] R. M. Cassidy and S. Elchuk, "Application of High Performance Liquid Chromatography to the Analysis of Nuclear Materials," Journal of Liquid Chromatography \& Related Technologies, Vol. 4, No. 3, 1981, pp. 379-398. doi:10.1080/01483918108059943

[10] S. Hjerten, "Free Zone Electrophoresis," Chromatographic Reviews, Vol. 9, 1967, pp. 122-219. doi:10.1016/0009-5907(67)80003-6

[11] A. K. Malik, "Metal Analysis with Capillary Zone Electrophoresis," Methods in Molecular Biology, Vol. 328, 2008, pp. 21-42. doi:10.1007/978-1-59745-376-9_2

[12] J. S. Fritz, "Recent Developments in the Separation of Inorganic and Small Organic Ions by Capillary Electrophoresis," Journal of Chromatography A, Vol. 884, No. $1-2,2000$, pp. 261-275. doi:10.1016/S0021-9673(00)00186-2

[13] A. R. Timerbaev, "Capillary Electrophoresis of Inorganic Ions: An Update," Electrophoresis, Vol. 25, 2004, pp. 4008-4031. doi:10.1002/elps.200406111

[14] A. R. Timerbaev, "Recent Trends in CE of Inorganic Ions: From Individual to Multiple Elemental Species Analysis," Electrophoresis, Vol. 28, 2007, pp. 3420-3435. doi:10.1002/elps.200600491

[15] A. R. Timerbaev, "Inorganic Species Analysis by CE An Overview for 2007-2008," Electrophoresis, Vol. 31, 2010, pp. 192-204. doi:10.1002/elps.200900397

[16] F. Qu and J. Lina, "Separation of Transition Metals in Nonaqueous Media with Capillary Electrophoresis," Journal of Chromatography A, Vol. 1068, 2005, pp. 169-174. doi:10.1016/j.chroma.2004.10.055

[17] F. Qu, J. Lin and Z. Chen, "Simultaneous Separation of Nine Metal Ions and Ammonium with Nonaqueous Capillary Electrophoresis," Journal of Chromatography A, Vol. 1022, 2004, pp. 217-221. doi:10.1016/j.chroma.2003.09.039
[18] E. Naujalis and A. Padarauskas, "Development of Capillary Electrophoresis for the Determination of Metal Ions Using Mixed Partial and Complete Complexation Techniques," Journal of Chromatography A, Vol. 977, 2002, pp. 135-142. doi:10.1016/S0021-9673(02)01350-X

[19] J. Gao, X. Sun, W. Yang, H. Fan, C. Li and X. Mao, "Separation and Determination of Six Metal Cations by Capillary Zone Electrophoresis," Journal of the Chilean Chemical Society, Vol. 53, No. 1, 2008, pp. 1431-1434. doi:10.4067/S0717-97072008000100020

[20] B. H. Li and X. P. Yan, "Rapid Speciation of Iron by On-Line Coupling of Short Column Capillary Electrophoresis and Inductively Coupled Plasma Mass Spectrometry with the Collision Cell Technique," Journal of Separation Science, Vol. 30, 2007, pp. 916-922. doi: $10.1002 /$ jssc. 200600405

[21] J. E. Sonke and V. J. M. Salters, "Capillary Electrophoresis-High Resolution Sector Field Inductively Coupled Plasma Mass Spectrometry," Journal of Chromatography A, Vol. 1159, 2007, pp. 63-74. doi:10.1016/j.chroma.2007.05.055

[22] R. Kautenburger and H. P. Beck, "Complexation Studies with Lanthanides and Humic Acid Analysed by Ultrafiltration and Capillary Electrophoresis-Inductively Coupled Plasma Mass Spectrometry," Journal of Chromatography A, Vol. 59, 2007, pp. 75-80. doi:10.1016/j.chroma.2007.03.092

[23] E. X. Vrouwe, R. Luttge, W. Olthuis and A. van den Berg, "Rapid Inorganic Ion Analysis Using Quantitative Microchip Capillary Electrophoresis," Journal of Chromatography A, Vol. 1102, 2006, pp. 287-293. doi:10.1016/j.chroma.2005.10.064

[24] G. L. Klunder, J. E. Andrews, P. M. Grant, B. D. Andresen and R. E. Russo, "Analysis of Fission Products Using Capillary Electrophoresis with On-Line Radioactivity Detection," Analytical Chemistry, Vol. 69, 1997, pp. 2988-2993. doi:10.1021/ac970042e

[25] B. Kuczewski, C. M. Marquardt, A. Seibert, H. Geckeis, J. V. Kratz and N. Trautmann, "Separtion of Plutonium and Neptunium Species by Capillary ElectrophoresisInductively Coupled Plasma-Mass Spectrometry and Application to Natural Groundwater Samples," Analytical Chemistry, Vol. 75, 2003, pp. 6769-6774. doi: $10.1021 / \mathrm{ac} 0347213$

[26] A. R. Timerbaev, "Metal Ions Analysis by Capillary Electrophoresis: New Possibilities in Separation and Detection," Journal of Capillary Electrophoresis, Vol. 1, 1995, pp. 14-23.

[27] F. Foret, S. Fanali, A. Nardi and P. Bocek, "Capillary Zone Electrophoresis of Rare Earth Metals with Indirect UV Absorbance Detection," Electrophoresis, Vol. 11, 1990, pp. 780-783. doi:10.1002/elps.1150110919

[28] Y. Shi and J. S. Fritz, "Separation of Metal Ions by Capillary Electrophoresis with A Complexing Electrolyte," Journal of Chromatography A, Vol. 640, 1993, pp. 473-479. doi:10.1016/0021-9673(93)80217-V

[29] A. R. Timerbaev, O. P. Semenova and O. M. Petrukhin, 
"Migration Behaviour of Metal Complexes in Capillary Zone Electrophoresis: Interpretation in Terms of Quantitative Structure-Mobility Relationships," Journal of Chromatography A, Vol. 943, 2002, pp. 263-274. doi:10.1016/S0021-9673(01)01462-5

[30] S. Pozdniakova, A. Padarauskas and G. Schwedt, "Simultaneous Determination of Iron(II) and Iron(III) in Water by Capillary Electrophoresis," Analytica Chimica Acta, Vol. 351, 1997, pp. 41-48. doi:10.1016/S0003-2670(97)00331-0

[31] B. Y. Deng, C. J. Zeng and W. T. Chan, "Speciation of Iron Using Capillary Electrophoresis Inductively Coupled Plasma Atomic Emission Spectrometry," Spectroscopy and Spectral Analysis, Vol. 25, 2005, pp. 1868-1871.

[32] P. Blatný, F. Kvasnička and E. Kenndler, “Trace Determination of Iron in Water at the $\mu \mathrm{g} / \mathrm{l}$ Level by On-line Coupling of Capillary Zone Electrophoresis with UV Detection of the EDTA-Fe(III) Complex," Journal of Chromatography A, Vol. 757, 1997, pp. 297-302. doi:10.1016/S0021-9673(96)00668-1

[33] B. Baraj, M. Martinez, A. Sastre and M. Aguilar, "Simultaneous Determination of $\mathrm{Cr}(\mathrm{III}), \mathrm{Fe}(\mathrm{III}), \mathrm{Cu}(\mathrm{II})$ and $\mathrm{Pb}(\mathrm{II})$ as UV-absorbing EDTA Complexes by Capillary Zone Electrophoresis," Journal of Chromatography A, Vol. 695, 1995, pp. 103-111. doi:10.1016/0021-9673(94)01078-S

[34] G. Owens, V. K. Ferguson, M. J. Mclaughlin, I. Singleton, R. J. Reid and F. A. Smith, "Determination of NTA and EDTA and Speciation of Their Metal Complexes in Aqueous Solution by Capillary Electrophoresis," Environmental Science \& Technology, Vol. 34, 2000, pp. 885-891. doi:10.1021/es990309m

[35] S. Schäffer, P. Gared, C. Dezael and D. Richard, "Direct Determination of Iron(II), Iron (III) and Total Iron as UV-absorbing Complexes by Capillary Electrophoresis," Journal of Chromatography A, Vol. 740, 1996, pp. 151-157. doi:10.1016/0021-9673(96)00121-5

[36] W. Buchberger and S. Mülleder, "Determination of Chelating Agents and Metal Chelates by Capillary Zone Electrophoresis," Mikrochimica Acta, Vol. 119, 1995, pp. 103-111. doi:10.1007/BF01244859

[37] P. Kuban, P. Kuban and V. Kuban, "Simultaneous Capillary Electrophoretic Separation of Small Anions and Cations after Complexation with Ehylenediaminetetraacetic Acid," Journal of Chromatography A, Vol. 836, 1999, pp. 75-80. doi:10.1016/S0021-9673(98)00980-7

[38] M. Xavier, P. R. Nair, K. V. Lohithakshan, S. G. Marathe and H. C. Jain, "Determiantion of Uranium in the Presence of Iron and Plutonium by Ti(III) Reduction and Biamperometric Titration," Journal of Radioanalytical and Nuclear Chemistry, Vol. 148, 1991, pp. 251-256. doi:10.1007/BF02060358
[39] I. Ali, V. K. Gupta and H. Y. Aboul-Enein, "Metal Ion Speciation and Capillary Electrophoresis: Application in the New Millennium," Electrophoresis, Vol. 26, 2005, pp. 3988-4002. doi:10.1002/elps.200500216

[40] B. Baraj, A. Sastre, A. Merkoci and M. Martinez, "Determination of Chloride Complex of $\mathrm{Au}(\mathrm{III})$ by Capillary Zone Electrophoresis with Direct UV Detection," Journal of Chromatography A, Vol. 718, 1995, pp. 227-232. doi:10.1016/0021-9673(95)00655-9

[41] B. Baraj, A. Sastre, M. Martinez and K. Spahiu, "Simultaneous Determination of Chloride Complexes of Pt(IV) and Pd(II) by Capillary Zone Electrophoresis with Direct UV Absorbance Detection," Analytica Chimica Acta, Vol. 319, 1996, pp. 191-197. doi:10.1016/0003-2670(95)00472-6

[42] C. Hennig, K. Servaes, P. Nockemann, K. V. Hecke, L. V. Meervelt, J. Wouters, L. Fluyt, C. Görller-Walrand and R. V. Deun, "Species Distribution and Coordination of Uranyl Chloro Complexes in Acetonitrile," Inorganic Chemistry, Vol. 47, 2008, pp. 2987-2993. doi:10.1021/ic7014435

[43] C. Hennig, J. Tutschku, A. Rossberg, G. Bernhard and A. C. Scheinost, "Comparative EXAFS Investigation of Uranium(VI) and -(IV) Aquo Chloro Complexes in Solution Using a Newly Developed Spectroelectrochemical Cell," Inorganic Chemistry, Vol. 44, 2005, pp. 6655-6661. doi:10.1021/ic048422n

[44] N. J. Welham, K. A. Malatt and S. Vukcevic, "The Effect of Solution Speciation on Iron-Sulphur-Arsenic-Chloride Systems at 298K," Hydrometallurgy, Vol. 57, 2000, pp. 209-223. doi:10.1016/S0304-386X(00)00121-3

[45] W. Liu, B. Etschmann, J. Brugger, L. Spiccia, G. Foran and B. McInnes, "UV-Vis Spectrophotometric and XAFS Studies of Ferric Chloride Complexes in Hyper-Saline LiCl Solutions at 25-90 C," Chemical Geology, Vol. 231, 2006, pp. 326-349. doi:10.1016/j.chemgeo.2006.02.005

[46] W. Walkowlak, D. Bhattacharyya and R. B. Grieves, "Selective Foam Fractionation of Chloride Complexes of Zinc(II), Cadmium(II), Mercury(II) and Gold(III)," Analytical Chemistry, Vol. 48, 1976, pp. 975-979. doi:10.1021/ac60371a036

[47] J. Bjerrum, "Determiantion of Small Stability Constants, A Spectrophotmetric Study of Copper(II) Chloride Complexes in Hydrochloric Acid," Acta Chemica Scandinavica - Series A, Vol. 41, 1987, pp. 328-334. doi:10.3891/acta.chem.scand.41a-0328

[48] H. Engelhardt, W. Beck and T. Schmitt, "Capillary Electrophoresis," Friedrich Vieweg \& Sohn Verlagsgesellschaft mbH, Braunschweig/Wiesbaden, 1996.

[49] DAE-Interlaboratory Comparison Experiment (ILCE) for Trace Metal Assay of Uranium, Phase-II Experimets: Development of Certified $\mathrm{U}_{3} \mathrm{O}_{8}$ Reference Materials, Document, BARC, India, February 2002. 